may be presumed to be intended for the pipistrelle, the tail is entirely omitted, so that there is nothing to support the median extension of the interfemoral membrane! The following remarkable sentence (p. 202), we are glad to acknowledge, is not typical of the author's style:- “The koala's habits are sluggish, and though able to climb well, moves about the trees in a most deliberate manner."

R. L.

Queen-Rearing in England, and Notes on a Scentproducing Organ in the Abdomen of the WorkerBee, the Honey-Bees of India, and Enemies of the Bee in South Africa. By F. W. L. Sladen. (Houlston and Sons, 1905.)

THE scope of this little work by a practical beekeeper is sufficiently indicated by its title, and the bulk of its contents has already appeared in the British Bee Journal and the Entomologist's Monthly Magazine. There is a coloured frontispiece representing the queen and worker of the Golden Itallian bee, and there are numerous text-illustrations of no remarkable excellence After a chapter on queenrearing in nature, several chapters are devoted to the best artificial means of securing a supply of queens for multiplying or improving bee-colonies; and a brief account is given of different races called the Italian (or Ligurian) Bee, the Golden Italian Bee, and Carniolan Bee, and the Cyprian Bee. In a later chapter Mr. Sladen remarks that when vibrating their wings, and especially when swarming, bees produce a peculiar tune which has been supposed to attract their comrades; but the author thinks the attraction is at least partly due to a powerful scent emitted when a membrane situated between the fifth and sixth dorsal segments of the abdomen is exposed. This is fully described and figured. Short chapters on the honey bees of India (Apis dorsata, florea, and indica), and on enemies of bees in South Africa; "Bee Pirates" (sandwasps belonging to the genera Palarus and Philanthus), a Tachinide parasite in the abdomen; and a species of Chelifer conclude the work.

Physical Experiments. By N. R. Carmichael. Pp. $\mathrm{xi}+\mathrm{I27}$; with diagrams. (Kingston, Ontario: $\mathrm{R}$. Uglow and Co., I904.)

ANyone drawing up an elementary course of mechanical and physical experiments, and wishing for a manual to accompany it so as to make the preparation of a special volume unnecessary, could hardly do better than adapt his course to the manual before us. It contains just the short description which would otherwise be produced by some copying process for distribution to a class, or, failing this, would pron bably be written on a blackboard. That is to say, there is just enough description to indicate to a pupil what he is expected to do, and which would be copied by him into his notebook. A teacher will require to amplify the book verbally, either in the course of a short demonstration at the beginning of the class, or, if his lectures and the practical work run together very well, this might sometimes be done in the course of the lectures. The aim that Mr. Carmichael has had before him has been to state concisely the nature of the quantity to be measured in each experiment and the theory underlying the method suggested. Descriptions of instruments are entirely omitted, as the students are expected to have the apparatus given them by an instructor.

With regard to the selection of experiments, the object has been to give students who have but a limited time for laboratory work a practical acquaintance with as many physical quantities as possible. The fact that the author is a teacher in a school of mining is a guarantee that the technical student is intended to be served; but it is the more academic, but equally necessary, side of his training that is here catered for.

\section{An Introduction to Elementary Statics (Treated} Graphically). By R. Nettell. Pp. 64. (London : Edward Arnold, 1905.) Price $2 s$.

THIs book consists of a set of graduated exercises in graphical statics. The first seventy, about half the total number, are restricted to problems on the equilibrium of three forces at a point, and are intended to be worked by means of the parallelogram of forces. In succeeding problems the triangle of forces and the polygon of forces are introduced. The principle of moments is also employed. A few examples are given of the determination of the centre of gravity of simple plane figures, and in the final examples the subject is carried as far as the equilibrium of four non-concurrent forces in one plane. The link polygon is not used, so that parallel forces are scarcely referred to. It will be seen how extremely limited is the ground covered by this book. The constructions are not founded on or verified by experimental work of any kind. No vectors other than force vectors are introduced. Trigonometrical calculations, even of the simplest kind, are rigidly excluded. The book is intended to be used by classes of young boys, but its scheme does not harmonise with the ideas now prevalent as to the way in which elementary mathematics should be taught to youths.

The Elements of the Differential and Integral Calculus. By D. F. Campbell. Pp. $x+364$. (New York: The Màcritlan Co.; London: Macmillan and Co., Ltd., I904.) Price $7 s, 6 d$.

THis book seems well adapted to serve as a text-book for a first course in the differential and integral calculus. Fourteen chapters deal with the differential calculus and its applications to maxima and minima values, expansions in series, and the geometry of plane curves. The fundamental ideas of integration are very fully explained, the second fourteen chapters being devoted to the integral calculus and its application to finding plane areas, lengths of curves, areas of surfaces, and volumes. In a short chapter dealing with approximate integration, the first and second elliptic integrals are introduced, and three-figure tables for $\mathrm{F}(k, \phi)$ and $\mathrm{E}(k, \phi)$ are given. $\mathrm{A}$ few elementary chapters on mechanics have been introduced, so that the student may be able to view from the mechanical, rather than from the purely mathematical, side the principles of attraction, centre of gravity, and moment of inertia. Numerous exercises, with answers, are given with each chapter. The diagrams are clear, and the type is excellent.

Völkerpsychologie. By Wilhelm Wundt. Vol. i. Die Sprache. Second revised edition. 2 parts. Pp. $x v+667, x+673$. (Leipzig: Wilhelm Engelmann; London: Williams and Norgate, 1904.) Price $14 s$. net and ${ }_{5} 5$. net; bound, I $7 s$. net and $18 s$, net.

THE first volume of this monumental work has reached a second edition, some sixty or seventy pages bulkier than its predecessor (reviewed in NATURE on January I6, I902). The most important changes affect the fourth chapter, Der Lautwandel, the sixth. Die Wortformen, and some parts of the theory of the sentence. A first edition of the other volumes, dealing with myth and custom, has not yet appeared; it is to be hoped that it will not be unduly delayed by the necessity of revising the present instalment, and that in any parts still to appear the wood will be less closely concealed by the trees.

No. I 858 , vOL. 72$]$ 